\title{
Modeling Volatility of Nigeria Stock Exchange Using Multivariate GARCH Models
}

\author{
Monday Osagie Adenomon ${ }^{1}$; John Joseph Mbuk ${ }^{1}$ \& Haruna Umar Yahaya ${ }^{2}$ \\ 1. Department of Statistics, Nasarawa State University, Keffi, Nigeria \\ 2. Department of Statistics, University of Abuja, Nigeria \\ adenomonmo@nsuk.edu.ng; johnjoekoko@gmail.com; yahagumau@gmail.com
}

\begin{abstract}
The aim of this research work was to provide model for predicting stock volatility in Nigeria Stock market. To achieve this, monthly data for Nigerian stock exchange, Exchange rate, Share index and inflation rate was collected for a period of January 1990 to December 2016.The descriptive statistics revealed these variables to exhibit volatility as a characteristics of financial time -varying series. DCC Model was fitted, were the coefficients for all the parameters and that of the correlation-Targeting (rho_21) are both negative and positive and tend very close to 1 and -1 , indicating that high persistence in the conditional variances. The Model DCC, satisfied the properties of a good model of conditional mean and variance of the confidential Interval (C.I) of 1 and -1 , that is, the conditional variances are finites and their series are strictly stationary. This therefore implies that the Nigerian Stock Exchange, Exchange rate, share index and Inflation rate will experience a non-steady shock in the Stock market. However Each of these variables have different length of recovery (volatility half- life) ranging from $1.5 \mathrm{month}, 6.5 \mathrm{months}$, 6months to 2,4 months for stock exchange, exchange rate, share index and inflation rate respectively. By implication, the volatility of these variables had a long memory, persistence and mean-reverting.
\end{abstract}

Keywords: Volatility; Stocks; Persistence; Exchange Rate, Inflation Rate; Financial Time Series; Generalized Autoregressive Conditional Heteroscedasticity (GARCH); Multivariate GARCH (MGARCH)

\subsection{Introduction}

Multivariate GARCH models were initially developed in the late 1980s and the first half of the $1990 \mathrm{~s}$, and after a period of tranquility in the second half of the 1990s, this area seems to be experiencing again a quick expansion phase. The univariate $\mathrm{ARCH}$ model introduced in Engle (1982) has been extended in several directions by allowing formultiple time series, conditional covariance terms in the mean, and own past conditionalcovariances in each of the covariance equations. Bollerslev et al., (1988) originally proposed the basic framework of MGARCH which extends the univariate GARCH into the vectorized conditional-variance matrix. This VECH model involves a large number of parameters estimation. In order to make estimation more tractable, Bollerslev et al., (1988) proposed the diagonal VECH model. However, this type of MGARCH model could not be used to examine spill-over effects since it simplified the correlation between parameters. The factor GARCH introduced by Engle et al., (1990) reduces 
the number of parameters to $\mathrm{O}(\mathrm{k} 2)$ but empirical studies reveal its poor performance on low land negative correlations. Alexander (2000) further demonstrates how to apply factor (Orthogonal) GARCH models, which limit the factors accounting for the amount of volatility. The most attractive feature of this kind of MGARCH model is generous enough to provide a method for estimating any variance-covariance matrix using univariate GARCH models. However, Sheppard (2003) criticized this approach in that it is hard to interpret the coefficients on the univariate GARCH model and that it performs poorly for less correlated systems such as individual equities since it reduces the number of parameters to O(k). Engle and Kroner (1995) made improvements based on the work of Baba Engle, Kraft and Kroner and created a general quadratic form for the covariance equation which successfully eliminated the positive definiteness problem of the original VECH model. In the full general BEKK model, the number of parameters needed to be estimated is $\mathrm{O}(\mathrm{k} 4)$, the standard BEKK estimation will involve $\mathrm{O}(\mathrm{k} 2)$ parameters. Other more plausible formulations of BEKK model include diagonal and scalar BEKK where the parameters are restricted to be either diagonal matrices or to be scalars. The most obvious shortcoming of those simplified BEKK models is that some information such as volatility spill-over effects are missing in the variance covariance matrix since the parameters have been reduced.

Bollerslev (1990) proposed the Constant Correlation (CC) model; although it still allows volatility time-varying, the conditional correlations are restricted to be time invariant. Tsui and $\mathrm{Yu}$ (1999) have found out that the constant correlation assumption can be rejected for certain assets which indicate that the $\mathrm{CC}$ model may not be generous enough. In the light of the prementioned limitations of various MGARCH models, Engle (2002) advocate a new class of MGARCH model which is named as Dynamic Conditional Correlation (DCC). Intuitively, the DCC model maintains the plausibility of the CCC model whilst still allowing for time-varying conditional correlation. Sheppard (2003) made a great contribution to the DCC model estimation by reducing the estimation of $\mathrm{MGARCH}$ to a series of univariate GARCH process plus an additional correlation estimator. According to Ling and Dhesi (2010), the specification of the univariate GARCH is generous to any GARCH process with normal distribution that satisfies the non-negative constraints and the stationary condition. This recent development is motivated by the usual phenomenon in multivariate modeling of the unequal or mismatching durations of different datasets. Patton (2006) proposed two maximum likelihood estimators (MLEs) of 
parameters of a multivariate model for time series with histories of different lengths. In comparing DCC with the BEKK model, it is found that, the prominent strength of the DCC model is that it does not suffer dimension hindrance and could be applied to any dimension. This is because the estimation can be decomposed into two steps: estimating the univariate GARCH and subsequently constructing a maximum likelihood function which has only two parameters. However, the DCC model imposes more restrictions on the type of dynamic effects than the BEKK model. In particular, the conditional variance of returns only depends on the past squared returns, some of which can cause the "volatility spillovers" to be excluded. Similarly, feedback from past volatilities or squared returns on correlations is severely limited in the DCC model (Micheal,2010) and (Ling \& Dhesi,2010).). Most scholars chooses the BEKK model to capture the volatility spillover effects and the DCC model to measure the dynamic conditional correlations.

This study aimed at modeling stock volatility in Nigeria Stock market using Multivariate GARCH.

\subsection{Empirical Review of Nigeria Stock Exchange}

Stock Exchange can simply be defined as an organized and regulated financial market where securities (bonds, notes, shares) are bought and sold at prices governed by the forces of demand and supply. Stock exchanges basically can be categorising into two which are primary and secondary markets (Friedmann \& Sanddorf, 2002). Stock market volatility can be said to be a measure for variation of price of a financial asset over time. It is essentially, concerned with the dispersion and not the direction of price changes. Issues of volatility in stock market behaviour are of importance as they shed light on the data generating process of the returns (Hongyu \& Zhichao, 2006). As a result, such issues guide investors in their decision making process because not only are the investors interested in returns, but also in the uncertainty of such returns and efforts toward financial sector reforms would be an exercise in futility if volatility of stock market is not addressed.

Stock exchange issue has attracted the attentions of researchers and statisticians all over the world. The ability to predict the stock price to meet the fundamental objectives of investors and operators of stock market for gaining more benefits cannot be overemphasized. Stock markets are influenced by numerous factors and this has created a high controversy in this field. Many 
methods and approaches for formulating forecasting models are available in the literature which comprises of both the empirical and theoretical literature on the Nigeria Stock exchange.

Several research and approaches have been carried out or used to model monthly returns from the Nigeria Stock Exchange in which are discussed below.

Bala, \& Takimoto (2017) investigated stock returns volatility spillovers in emerging and developed markets (DMs) using multivariate-GARCH (MGARCH) models and their variants. They analysed the impacts of global financial crisis (2007-2009) on stock market volatility interactions and modify the BEKK-MGARCH-type models by including financial crisis dummies to assess their impact on volatilities and spillovers. Their major findings reveal that correlations among emerging markets (EMs) are lower compared with correlations among DMs and increase during financial crises. Furthermore, they detected evidence of volatility spillovers and observed that own-volatility spillovers are higher than cross-volatility spillovers for EMs suggesting that shocks have not been substantially transmitted among EMs compared to DMs. They also found significant asymmetric behaviour in DMs while weak evidence is detected for EMs. Finally, the DCC-with-skewed- $t$ density model provided improved diagnostics compared to other models partly due to its taking into account fat tails and skewed features often present in financial returns.

Eke (2016) examined the statistical modeling of monthly returns from the Nigerian stock exchange using probability distributions (normal and logistic distributions) for the period, 1995 to 2014. He analyzed the data to determine the returns from the stock exchange, its mean and standard deviation in order to obtain the best suitable distribution of fit. Furthermore, comparative analysis was done between the logistic distribution and normal distribution. The findings proved that the logistic distribution is better than the normal distribution in modeling the returns from the Nigeria stock exchange due to its $\mathrm{p}$ - value which is greater than the $5 \%$ significance level of alpha and also because of its minimum variance.

Yaya et al. (2016) estimates the dynamic pattern of the Nigeria All Share Index (ASI) from January 3, 2006 to July 22, 2014. Parameter estimates of the models were obtained using the Quasi Maximum Likelihood (QML) approach, and in-sample conditional volatility forecasts from each of the models were evaluated using the minimum loss function approach. Among the classical volatility models, the initial results detected IGARCH-t as the best model for predicting volatility in the ASI. However, in estimating the GAS variants, the Beta-t-EGARCH model proves to predict the volatility in the stock returns better than the IGARCH-t. The estimates could not improve further when the skewed version 
of the Student-t distribution was considered. We therefore recommend the GAS, EGAS and AEGAS family models in predicting jumps, outliers and asymmetry in financial time series modelling. Olayiwola et al. (2016) focused their studies on the returns on the All-Share Index of the Nigerian stock exchange on the Nigerian economy. A time plot was used to examine the trend, seasonality, and discontinuity of the data. Box Jenkins approach with $\mathrm{R}$ statistical package was used to examine the stationary of Nigeria All-Share Index. The parameters of the model were estimated using the maximum likelihood estimation techniques and Akaike Information Criteria (AIC) was used to check for the goodness of fit of the fitted model.

Murekachiro (2016) explored the comparative ability of different statistical and econometric volatility forecasting models in the context of Zimbabwe stock market. He considered two different models in his study. The volatility of the ZSE industrial index returns have been modeled by using a univariate Generalized Autoregressive Conditional Heteroskedasticity $(\mathrm{GARCH})$ models including both symmetric and asymmetric models that captures most common stylized facts about index returns such as volatility clustering, fat tails and leverage effect, these models are GARCH $(1,1)$ and exponential GARCH $(1,1)$. The first model he used for capturing the symmetry effect whereas the second model is for capturing the asymmetric effect. The study used a stock market average daily industrial index from Zimbabwe (ZSE index), a country not previously considered in the volatility literature, for the period 19 February 2009 to 31 December 2014. Basing on the empirical results presented, the following can be concluded. ZSE data showed a significant departure from normality and existence of conditional heteroskedasticity in the residuals series. For all periods specified, the empirical analysis evidenced that asymmetric EGarch $(1,1)$ model outperform the symmetric Garch $(1,1)$ model on forecasting future volatility after using two different evaluation techniques of Error measures statistics and regression based analysis. Future studies should consider the general extensions of Garch models, in particular symmetric and asymmetric Garch (p; q) rather than symmetric and asymmetric Garch $(1 ; 1)$ model. This general extension is helpful because such higher order models are often useful when long span of data is used. Therefore, with additional lags such models allow both fast and slow decay of information.

Emenike. et al (2014) examined domestic volatility transmission between sectors of the Nigerian economy using Multivariate Generalised Autoregressive Conditional Heteroscedasticity $(\mathrm{MGARCH})$ procedure. They centre their focus on evaluating the nature and direction shock and 
volatility transmission between the banking sector, the consumer goods sector. Their results indicate existence of unidirectional shock and volatility transmission from the banking sector to the consumer goods sector, and bidirectional shock and volatility transmission between the consumer goods. These findings have crucial implications for domestic portfolio selection and management through the hedging opportunities available in the NSE sectors. Onwukwe et al. (2011) investigated the time series behaviour of daily stock returns of four firms listed in the Nigerian Stock Market from 2nd January, 2002 to 31st December, 2006, using three different models of heteroscedastic processes, namely: GARCH $(1,1)$, EGARCH $(1,1)$ and GJR-GARCH models respectively. The four firms whose share prices were used in this analysis are UBA, Unilever, Guinness and Mobil. All the return series exhibit leverage effect, leptokurtosis, volatility clustering and negative skewness, which are common to most economic financial time series. Except for Guinness, other series display significant level of second-order autocorrelation, satisfying covariance-stationary condition. These models were estimated assuming a Gaussian distribution using Brendt-Hall-Hall-Hausman (BHHH) algorithm's program in Eview software platform. The estimation results reveal that the GJR-GARCH $(1,1)$ gives better fit to the data and are found to be superior both in-sample and out-sample forecasts evaluation.

Stelzer (2008) established that all VEC models not representable in the simplest BEKK form contain matrices as parameters which map the vectorised positive semi-definite matrices into a strict subset of themselves. Moreover, a general result from linear algebra is presented implying that in dimension two the models are equivalent and in dimension three a simple analytically tractable example for a VEC model having no BEKK representation is given. Okafor (1985) \& Anyafo (1994) identify securities traded based on the nature of rights and control exercised by US, security-holder. Hence, this ultimately depends on the type of security held. In that regard, Okafor (1996) identifies classification of securities that determine the right of a holder.

\section{Model Specification}

\subsection{Multivariate GARCH (MGARCH) model}

Multivariate GARCH models have been studied intensively in recent years and many different specifications have been used in the literature (Bauwens, Laurent \&Rombouts, 2006) for a comprehensive overview and Boussama $(1998,2006)$ for a detailed discussion on strict 
stationarity and geometric ergodicity. In this paper, the multivariate GARCH (MGARCH) models to be considered include BEKK, CCC, DCC

\subsection{Baba, Engle, Kraft and Kroner (BEKK) Model}

For an estimated multivariate GARCH model to be plausible, the parameter $\Sigma_{t}$ is required to be positive definite for all values of the disturbances. Engle \& Kroner (1995) proposed a quadratic formulation for the parameters that ensured positive definiteness. This became known as the BEKK model (Brooks et al., 2003). This model is relatively parsimonious and suitable for a large set of assets because its number of parameters grows linearly with the number of assets(De Goeij et al., 2004). The BEKK model is given as shown in the form below.

$$
\Sigma_{t}=C_{0} C_{0}^{\prime}+\sum_{k=1}^{K} \sum_{i=1}^{q} A_{k i}^{\prime} \varepsilon_{t-i} \varepsilon_{t-1}^{\prime} A_{k i}+\sum_{k=1}^{K} \sum_{i=1}^{p} B_{k i}^{\prime} \Sigma_{t-i} B_{k i}
$$

where $C_{0}$ is a lower triangular matrix, $A_{k i}$ and $B_{k i}$ are $N \times N$ parameter matrices.

Based on the symmetric parameterization of the model, $\Sigma_{t}$ is almost surely positive definite provided that $C_{0} \times C_{0}^{\prime}$ is positive definite (Tsay, 2005).

Engle and Kroner (1995) proved that the necessary condition for the covariance stationarity of the BEKK model is that the eigenvalues, that is the characteristic roots of, $\sum_{i=1}^{q} \sum_{k=1}^{K}\left(A_{i k}^{*} \otimes A_{i k}^{*}\right)+\sum_{i=1}^{p} \sum_{k=1}^{K}\left(B_{i k}^{*} \otimes B_{i k}^{*}\right)$ should be less than one in absolute value. Thus, the process can still render stationary even if there exists an element with a value greater than one in the matrix. Obviously, this condition is different from the stationarity condition required by univariate GARCH model: that the sum of ARCH and GARCH terms has to be less than one (Pang et al, 2002).

The $\operatorname{BEKK}(1,1, \mathrm{~K})$ model is defined as:

$$
\Sigma_{t}=C_{0} C_{0}^{\prime}+\sum_{k=1}^{K} \sum_{i=1}^{q} A_{k}^{\prime} \varepsilon_{t-1} \varepsilon_{t-1}^{\prime} A_{k}+\sum_{k=1}^{K} \sum_{i=1}^{p} B_{k}^{\prime} \Sigma_{t-1} B_{k},
$$

where $C_{0}, A_{k}$ and $B_{k}$ are $N \times N$ parameter matrices, but $C_{0}$ is upper triangular. We can also write $C_{0} \times C_{0}^{\prime}$. Positivity of $\Sigma_{t}$ is guaranteed if $\Sigma_{0} \geq 0$. Here, there are 11 parameters, against 21 in the VEC model (Bauwens, 2005). This model allows for dynamic dependence between the volatility series (Tsay, 2005). 
The diagonal and scalar BEKK models can be defined as follows:

i. The diagonal BEKK model. Take, $A_{k}$ and $B_{k}$ as diagonal matrices. For this case, the BEKK model is a restricted version of the VEC model with diagonal matrices (Bauwens, 2005; Franke et al, 2005).

ii. The scalar BEKK model. , $A_{k}=a_{k} \times U, B_{k}=b_{k} \times U$ Where a and $\mathrm{b}$ scalars and $\mathrm{U}$ is a matrix of ones.

The diagonal BEKK model is given by the following equations:

$$
\begin{gathered}
\sigma_{t=\mathrm{CC}^{\prime}+a \varepsilon_{t-1} \varepsilon_{t-1}{ }^{\prime} a^{\prime}+b \sigma_{t-1} b^{\prime}} \\
\sigma_{11, t}=c_{11}^{2}+a_{11}^{2} \varepsilon_{1, t-1}^{2}+b_{11}^{2} \sigma_{11, t-1} \\
\sigma_{22, t}=c_{11}^{2}+c_{22}^{2}+a_{22}^{2} \varepsilon_{2, t-1}^{2}+b_{22}^{2} \sigma_{22, t-1} \\
\sigma_{12, t}=\sigma_{21, t}=c_{11} c_{22}+a_{11} a_{22} \varepsilon_{1, t-1} \varepsilon_{2, t-1}+b_{11} b_{22} \sigma_{12, t-1}
\end{gathered}
$$

This model exhibits essentially the same problems as the full BEKK model there is no parameter in any equation that exclusively governs a particular covariance equation. Hence, it is not clear whether the parameters for $\sigma_{12}$ are just the result of the parameter estimates for $\sigma_{11}$ and $\sigma_{22}$, or if the covariance equation alters the parameter estimates of the variance equations. In addition, the model is not very flexible and can therefore be misspecified. But in a case where the covariance exhibits a different degree of persistence than the volatilities, it is therefore clear that either the volatility or the covariance process is misspecified (Baur, 2004).

The $\operatorname{BEKK}(1,1,1)$ model $\Sigma_{t}=\Omega+A^{\prime} \varepsilon_{t-1} \varepsilon_{t-1}^{\prime} A+B^{\prime} \Sigma_{t-1} B$ can be written as a VEC mode (subject to restrictions) using the formula.

$$
\operatorname{VEC}\left(\Sigma_{t}\right)=\operatorname{VEC}(\Omega)+(A \otimes A) \operatorname{VEC}\left(\varepsilon_{t-1} \varepsilon_{t-1}^{\prime}\right)+(B \otimes B)^{\prime} \operatorname{VEC}\left(\Sigma_{t-1}\right)
$$

Hence, the BEKK model is weakly stationary if the eigenvalues of $(A \otimes A)+(B \otimes B)$ are smaller than one in modulus, and thus

$$
\operatorname{VEC}\left(\Sigma_{t}\right)=\left(I_{N^{2}}-(A \otimes A)^{\prime}-(B \otimes B)^{\prime}\right) \operatorname{VEC}(\Omega)
$$

\subsection{Constant Conditional Correlation (CCC) model}

Correlation models are based on the decomposition of the conditional covariance matrix into Conditional standard deviations and correlations. The simplest multivariate correlation model 
that is nested in the other conditional correlation models, is the Constant Conditional Correlation (CCC-) GARCH model of Bollerslev (1990). In this model, the conditional correlation matrix is time-invariant, so the conditional covariance matrix can be expressed as follows:

$$
\Sigma_{t} \equiv\left[\sigma_{i j, t}\right]=D_{t} \rho_{t} D_{t}
$$

where $\rho_{t}$ is the $N \times N$ conditional correlation matrix of $\varepsilon_{t}$, and $D_{t}$ is $N \times N$ diagonal matrix consisting of the conditional standard deviations of elements of $\varepsilon_{t}\left(\right.$ i.e. $\left.D_{t}=\operatorname{diag}\left\{\sqrt{\sigma_{11, t}}, \ldots, \sqrt{\sigma_{N N, t}}\right\}\right)$.

Because $\rho_{t}$ is symmetric with unit diagonal elements, the time evolution of $\Sigma_{t}$ is governed by that of the conditional variances $\sigma_{11, t}$ and the elements $\rho_{i j, t}$ of $\rho_{t}$, where $j<i$ and $1 \leq i \leq N$. Therefore, to model the volatility of $\varepsilon_{t}$, it suffices to consider the conditional variances and correlation coefficients of $\varepsilon_{i t}$ (Tsay, 2005). The conditional variances $\sigma_{11, t}$ are modeled by a univariate GARCH model. Hence,

$$
\sigma_{11, t}=\rho_{i j, t} \sqrt{\sigma_{i i, t} \sigma_{j j, t}} \forall_{i \neq j}
$$

Positivity of $S_{t}$ follows from the positivity of $\rho_{t}$ and that of each $\sigma_{i i, t}$ (Bauwens, 2005). As we said before, it is often difficult to verify the condition that the conditional variance matrix of an estimated multivariate GARCH model is positive definite. Furthermore, such conditions are often very difficult to impose during the optimization of the log-likelihood function. However, if we postulate the simple assumption that the correlations are time invariant, these difficulties elegantly disappear (Tse, 2000). Bollerslev (1990) suggested a multivariate GARCH model in which all conditional correlations are constant and the conditional variances are modeled by univariate GARCH models. This is so-called CCC model (constant conditional correlation) (Franke et al, 2005). The constant conditional correlation model (CCC) is defined as

$$
\rho_{t}=\rho=\left[\rho_{i j}\right], \rho_{i i}=1
$$

Hence

$$
\sigma_{11, t}=\rho_{i j \sqrt{\sigma_{i i, t} \sigma_{j j, t}}} \forall_{i \neq j}
$$


and the dynamics of the covariances is determined only by the dynamics of the two conditional variances. There are $\frac{N(N-1)}{2}$ parameters in $\rho$ (Bauwens, 2005).

Because of its simplicity, the CCC model has been very popular in empirical applications. A specific member of the group of CCC models is obtained by further constraining the correlations to be zero. This model is denoted as the no correlation (NC) model. Thus the CCC model is given by

$$
\begin{gathered}
\sigma_{i i, t}=c_{i}+\sum_{h=i}^{p} a_{h i} \varepsilon_{t-h, i}^{2}+\sum_{h=1}^{q} b_{h i} \sigma_{t-h, i} \quad i=1, \ldots, k \\
\sigma_{i j, t}=\rho_{i j} \sqrt{\sigma_{i i, t} \sigma_{j j, t}} \quad 1 \leq i<j<k
\end{gathered}
$$

and the NC model is its special case with $\rho_{i j}=0 \quad$ (Tse, Tsui,1999). The restriction that the constant conditional correlations, and thus the conditional covariances, are proportional to the product of the corresponding conditional standard deviations highly reduces the number of unknown parameters and thus simplifies estimation (Bauwens et al., 2006).

\subsection{The Dynamic Conditional Correlation Model}

This model was developed by Engle et al (2011). The Dynamic Conditional Correlation models is

$$
H_{\mathrm{t}}=D_{\mathrm{t}} R_{\mathrm{t}} D_{\mathrm{t}}
$$

Where $H_{\mathrm{t}}$ is the covariance matrix and $\mathrm{Dt}$ is an $\mathrm{n} \mathrm{x}$ matrix of the conditional correlation of the returns. The diagonal matrix Dt is expressed as

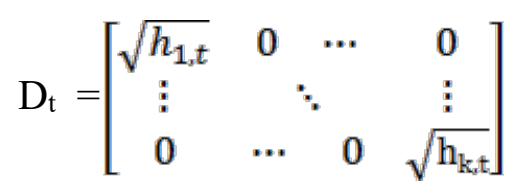

This matrix consists of the univariate GARCH models. Furthermore, $H_{\mathrm{t}}$ has to be positive definitive, which is automatically obtained while $R_{\mathrm{t}}$ is a correlation matrix that is symmetric by definition. When this matrix is defined, two requirements are needed. Firstly, $H$ tneed to be positive definite since it is a covariance matrix. Secondly, the parts that belong to $R \mathrm{t}$ need to be less than one. This requirements are met through a decomposition: $R_{\mathrm{t}}=R_{\mathrm{t}}=\operatorname{diag}(\mathrm{qiit})^{-}$ Qtdiag(qiit) ${ }^{-1}$ for $\mathrm{I}=1$...n where 


$$
Q t=(1-a-b) Q+a \epsilon_{t-1} \epsilon_{t-1}{ }^{\prime}+\mathrm{b} Q_{\mathrm{t}-1}
$$

and $Q=\operatorname{cov}\left[\epsilon t \epsilon^{\prime} t\right]=\mathrm{E}\left[\epsilon t \epsilon^{\prime} t\right]$. Additionally, the parameters $\mathrm{a}$ and $\mathrm{b}$ are scalars and

\section{$\operatorname{diag}(\mathrm{Q})$}

Is used to rescale then parts of $Q t$ in order to fulfill that $|P i j|=\left|\frac{\text { qint }}{\sqrt{q} q i \text { it } j j t}\right| \leq 1$ and where $\sqrt{q n n t}$ is the content of the matrix diag (qiit). The estimate of $\mathrm{Q}$ is

$$
\bar{Q}=\frac{1}{T} \sum_{t=1}^{T} \epsilon t \epsilon^{\prime} t
$$

Moreover, the scalars a and $\mathrm{b}$ must be larger than zero, but the sum has to be less than one. One may note that these are conditions of the univariate GARCH to be stationary, but which is applied in the DCC model. (Orskaug, 2009)

\subsection{Estimation of Multivariate GARCH model}

Suppose the vector stochastic process $\left\{r_{t}\right\}$ (for $t=1, \ldots, T$ ) has conditional mean, conditional variance matrix and conditional distribution $\mu_{t}\left(\theta_{0}\right), \Sigma_{t}\left(\theta_{0}\right)$ and $p\left(r_{t} \mid \varsigma_{0}, I_{t-1}\right)$ respectively. Here, $\varsigma_{0}=\left(\theta_{0} \eta_{0}\right)$ is a $k$-dimensional parameter vector, and $\eta_{0}$ is the vector that contains the parameters of the distribution of the innovations $z_{t}$.Importantly, to justify the choice of the estimation procedure, we assume that the model to be estimated encompasses the true formulations of $\mu_{t}\left(\theta_{0}\right)$ and ( ) $\Sigma_{t}\left(\theta_{0}\right)$ (Bauwens et al, 2006). The procedure used most often in estimating $\theta_{0}$ involves the maximization of a likelihood function constructed under the assumption of an i.i.d. distribution for the standardized innovations $z_{t}$. The likelihood function for the i.i.d. case can then be viewed as a quasi-likelihood function (Bauwens et al., 2006). Consequently, one has to make an additional assumption on the innovation process by choosing a density function, denoted $g\left(z_{t}(\theta) ; \eta\right)$ where $\eta$ is a vector of nuisance parameters. Thus, the problem to solve is to maximize the sample log-likehood function $L_{T}(\theta, \eta)$ for the observation, with respect to the vector of parameters, $\varsigma=(\theta, \eta)$ where

$$
L_{T}(\varsigma)=\sum_{t=1}^{T} \log f\left(r_{t} \mid \varsigma, I_{t-1}\right)
$$




\subsection{Distribution forms and Estimation of GARCH models}

Estimation of GARCH models is based on the assumption of normality, Students $\mathrm{t}$ and Generalized Error Distribution (GED) for the innovations series $\varepsilon_{t}$. The log-likelihood from the normal distribution is

$$
l_{t}=-\frac{1}{2}\left[N \log (2 \pi)+\sum_{t=1}^{N} \frac{\varepsilon_{t}^{2}}{\sigma_{t}^{2}}+\sum_{t=1}^{S} \log \sigma_{t}^{2}\right]
$$

And with $\varepsilon_{t}=\sigma_{t} z_{t}$ where $z_{t}=\varepsilon_{t} / \sigma_{t}$ is the GARCH time series innovations and $N$ is the sample size of the time series. For the Student t-distribution, we have

$$
l_{t}=-\frac{1}{2}\left\{N \log \left(\frac{\pi(v-2) \Gamma(v / 2)^{2}}{\Gamma((v+1) / 2)^{2}}\right)+\sum_{t=1}^{N} \log \sigma_{t}^{2}+(v+1) \sum_{t=1}^{N} \log \left[1+\frac{\varepsilon_{t}^{2}}{\sigma_{t}^{2}(v-1)}\right]\right\}
$$

Where $\mathrm{v}$ is the degrees of freedom to be estimated and $\Gamma($.$) is the gamma function. For GED, it$ is

$$
l_{t}=-\frac{1}{2}\left\{N \log \left(\frac{\Gamma\left(v^{-1}\right)}{\Gamma\left(3 v^{-1}\right)(v / 2)^{2}}\right)+\sum_{t=1}^{N} \log \sigma_{t}^{2}+(v+1) \sum_{t=1}^{N}\left(\frac{\Gamma\left(3 v^{-1}\right) \varepsilon_{t}^{2}}{\sigma_{t}^{2} \Gamma\left(v^{-1}\right)}\right)^{v / 2}\right\}
$$

Where $\mathrm{v}$ is the tail thickness parameter.

\subsection{Model Selection Criteria}

The GARCH variants will be evaluated by Akaike's (1994) Information Criterion (AIC) and Schwarz (1978) Bayesian Information Criterion (SBIC), even though the statistical properties of the criteria in the GARCH context are yet to be known. The two criteria are given as,

$$
A I C=-2 N^{-1} l_{t}(\Theta)+2 N^{-1} k
$$

and

$$
S B I C=-2 N^{-1} l_{t}(\Theta)+2 k N^{-1} \operatorname{In}(N)
$$

Where $l_{t}(\Theta)$ is the maximum likelihood function conditioned on the parameter set.

\subsection{Mean Reversion and Calculation of half-life of volatility shock for a stationary}

The high or low persistence in volatility is generally captured in the GARCH coefficient(s) of a stationary GARCH model. For a stationary GARCH model, the volatility mean reverts to its long run level, at the rate given by the sum of ARCH and GARCH coefficients, which is generally close to one for a financial time series. 
The average number of time periods for the volatility to revert to its long run level is measured by the half-life of the volatility shock. The mean reverting rate $\left(\alpha_{1}+\beta_{1}\right)$ implied by most fitted model is usually very close to 1 . The magnitude of $\left(\alpha_{1}+\beta_{1}\right)$ controls the speed of mean reversion.

The half-life of a volatility shock is given by the formula:

$$
L_{\text {half }}=\frac{\ln 0.5}{\ln \left(\alpha_{1}+\beta_{1}\right)}
$$

The closer $\left(\alpha_{1}+\beta_{1}\right)$ is to one the longer is the half-life of a volatility.

If $\left(\alpha_{1}+\beta_{1}\right)>1$, the GARCH model is nonstationary and the volatility will eventually explode to infinity. (Banerjee and Sarkar, 2006)

\subsection{Source of Data}

The data for this research work being a secondary data were collected from Table A.4.7.3: Nigerian Stock Exchange Market Capitalization - Equities Only (N' Billion) in the Central Bank of Nigeria (CBN) Statistical Bulletin 2016 on all share index on the Nigeria stock exchange ranging from January 1990 to December 2016 including the data for Share index and exchange rate and that of inflation rate is gotten from the world bank development indicators and NBS (National Bureau of Statistics).

\subsection{Data Presentation and Analysis}

This section which is the most important part of this paper is made up of the data presentation, analysis and discussions of data from secondary sources. The volatility test using multivariate GARCH model on all the four economic variables (Nigeria Stock Exchange, Exchange rate, Share Index and Inflation rate) under consideration was carried out using E-views 9.0 (Economics-views) and Ox-metrics G@rch 7.0 software and the results are interpreted accordingly. The data used for this research work was obtained from the Centre Bank of Nigeria (CBN) statistical bulletin 2016 and the Nigeria Bureau of Statistics (NBS).

\section{Table 4.1: Descriptive Statistics Measure}

\begin{tabular}{|l|c|c|c|c|}
\hline & INFLATION_RATE & EXCHANGE_RATE & SHARE INDEX & STOCK_EXCHANGE \\
\hline Mean & 18.7427 & 101.2375 & 17752.57 & 3695.994 \\
\hline Median & 12.5000 & 118.4900 & 14086.30 & 877.3000 \\
\hline
\end{tabular}




\begin{tabular}{|l|c|c|c|c|}
\hline Maximum & 78.5000 & 309.7304 & 65652.38 & 14027.71 \\
\hline Minimum & 0.90000 & 7.862100 & 343.0000 & 14.84329 \\
\hline Std. Dev. & 17.50079 & 66.40664 & 14925.84 & 4306.888 \\
\hline Skewness & 1.879150 & 0.182202 & 0.765194 & 0.836800 \\
\hline Kurtosis & 5.434309 & 2.828902 & 2.972739 & 2.216580 \\
\hline Jarque-Bera & 269.8488 & 2.181128 & 31.53058 & 45.95599 \\
\hline Probability & 0.000000 & 0.336027 & 0.000000 & 0.000000 \\
\hline Sum & 6053.900 & 32699.70 & 5734079 & 1193806 \\
\hline Sum Sq. Dev & 98621.45 & 1419969 & $7.17 \mathrm{E}+10$. & $5.97 \mathrm{E}+09$. \\
\hline Observations & 324 & 324 & 324 & 324 \\
\hline
\end{tabular}

The descriptive measures on the Inflation rate, Exchange rate, Share Index and Stock exchange data were presented in Table 4.1 above. The result obtained shows that the mean of the series are 18.7427, 101.2375, 17752.57 and 3695.994 for Inflation rate, Exchange rate, Inflation rate, Share Index and Stock exchange respectively with the median values of 12.5000, 118.4900, 14086.30 and 877.3000 in that order and the standard deviation of Exchange rate which is 66.4066, Inflation rate is 17.50079 , Stock exchange is 14925.84 and Stock exchange is 4306.888 , it also shows the probability value (p-value) of both Inflation rate, Share Index and Stock exchange are 0.0000 which indicated that the data are not normally distributed, while 
Exchange rate has the probability value of 0.3360 which indicated normality. Exchange Rate

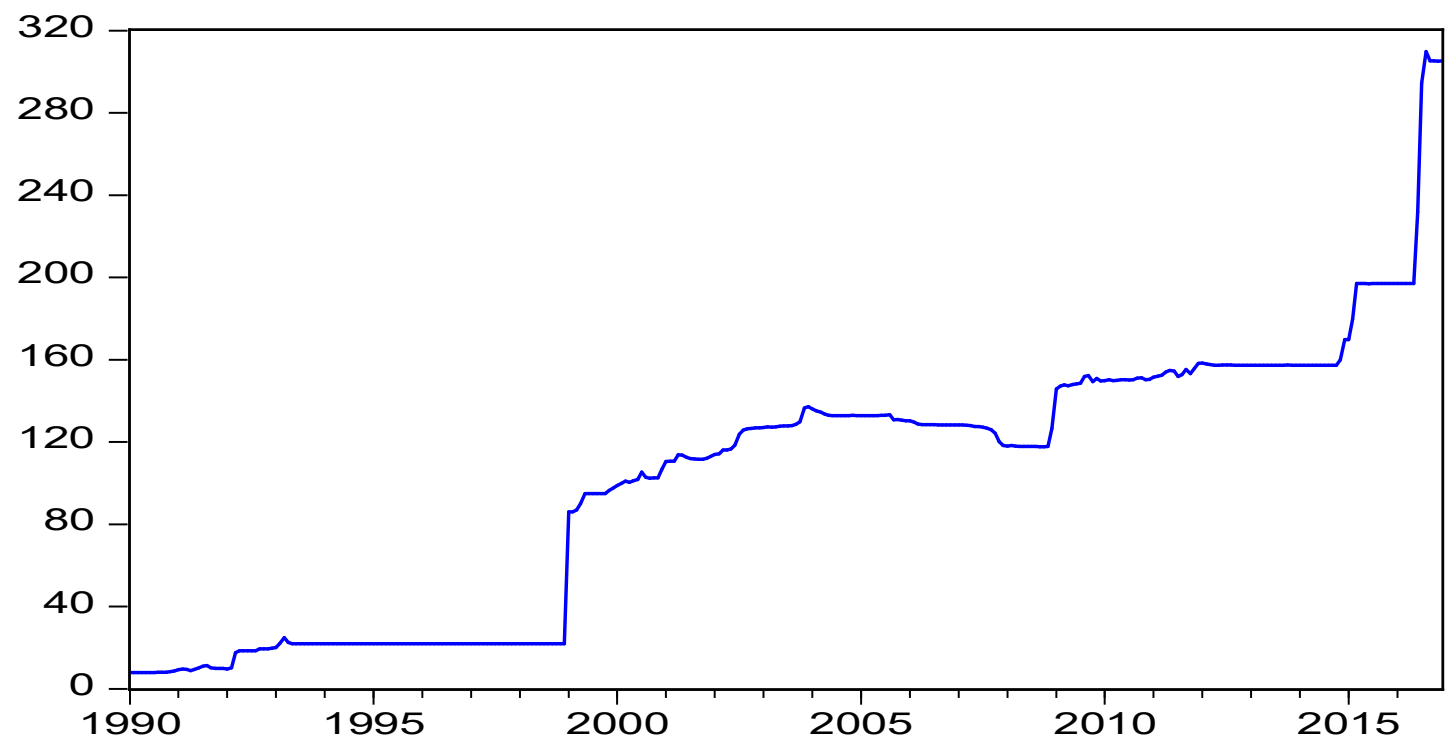

Figure 4.1 Trend of Exchange Rate

Figure 4.1 shows the trend of exchange rate in Nigeria where it was notice that there is only slightly increase towards the end of 1990 to mid-1993 with a stationary movement from early part of 1994 to 1999, a suddenly rise from that 1999 up to2005 and later go up and down with a slight increased upward.

\section{Inflation Rate}



Figure 4.2 Trend of Inflation Rate

Figure 4.2 shows the time plot of Inflation rate in Nigeria in which it was observed that there is rapid increase from the beginning of the year 1991 with a break in 1995 and an upward 
movement up to 1996 then experience a fall in the beginning of 1996 down to 1998 and later maintain a stationary trend down to2005 and an increase from 2016.

\section{Shareindex}

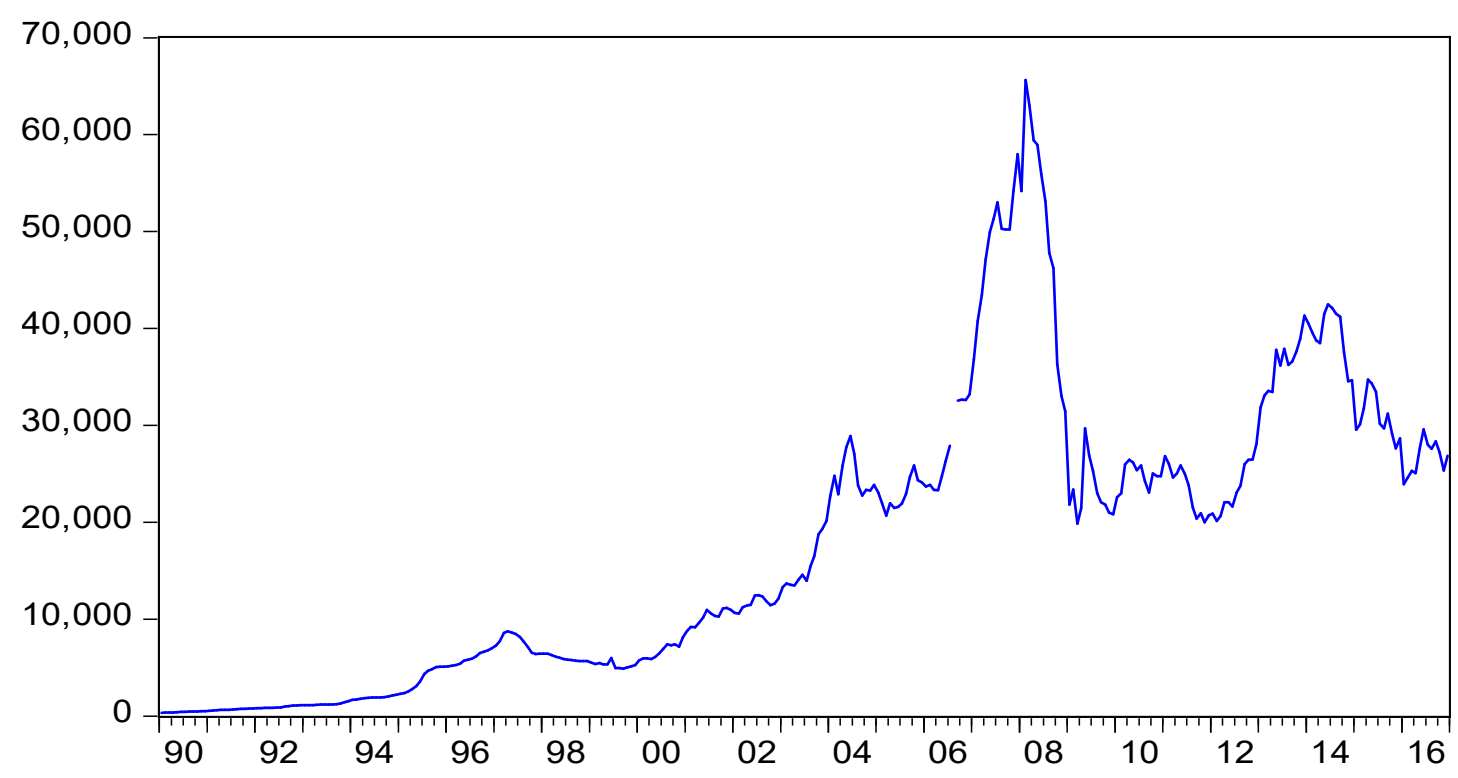

Figure 4.3 Trend of Share Index

Figure 4.3 shows the time plot of Share Index in Nigeria in which there is parallel movement from 1990 to 1993 with an increased which was notice from mid-1993 up 1997 and slightly increase to the end of 2003. Several breaks were observed with sharp upward movement from 2006 with a sharp downward 2008 and further toward 2016.

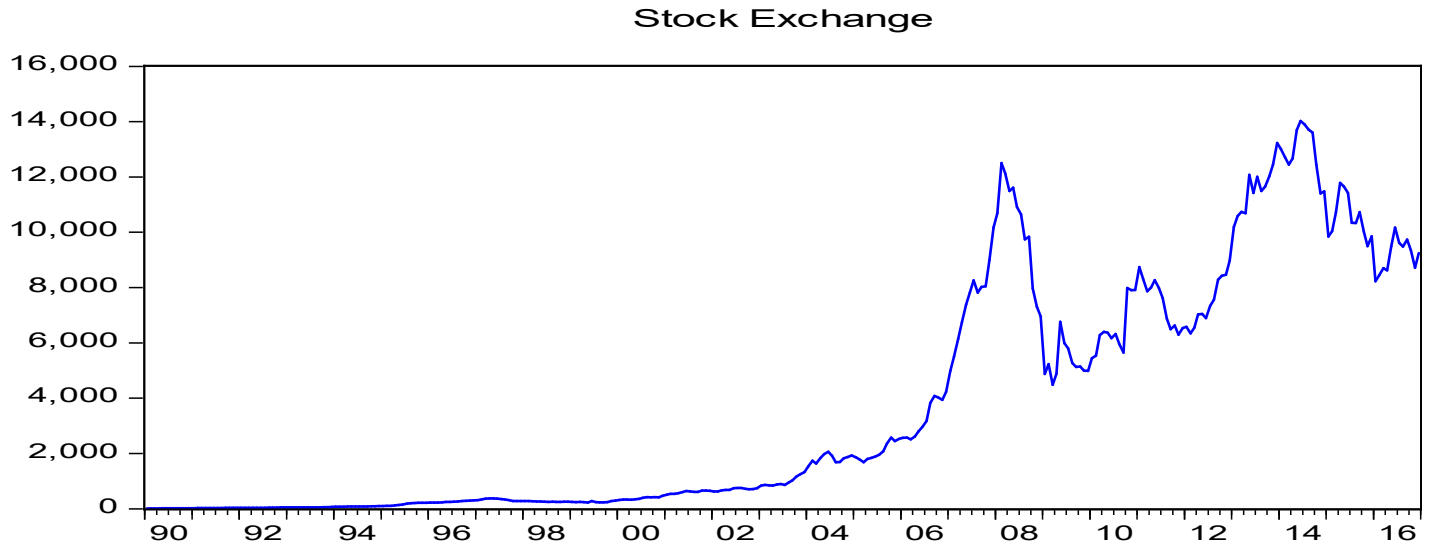

Figure 4.4 Trend of Stock Exchange 
Figure 4.4 above shows the trend of time plot of Stock Exchange in Nigeria where the trend was observed to be moving with parallel trend from 1990 to 1993 with a slightly incensement from 1994 with slow movement to 2002 and a sharp increase from 2004 to 2008 and a down fall trend from that 2008 to 2009 with a break in the early part of 2008 and finally experience a drop in 2013 down to 2016.

\subsection{Data Analysis using Ox Metrics Garch 7.0}

First we plot the return series of the four variables (Stock exchange, Exchange rate, Share Index and Inflation rate) to show periods of low and high volatilities, which signify volatility clustering. The four series of $a_{t}$ are shown in Figure 4.1. We see that all the four series have volatility clustering, i.e. periods with high volatility and periods with low volatility, which indicates that a GARCH model can be used to fit the data.
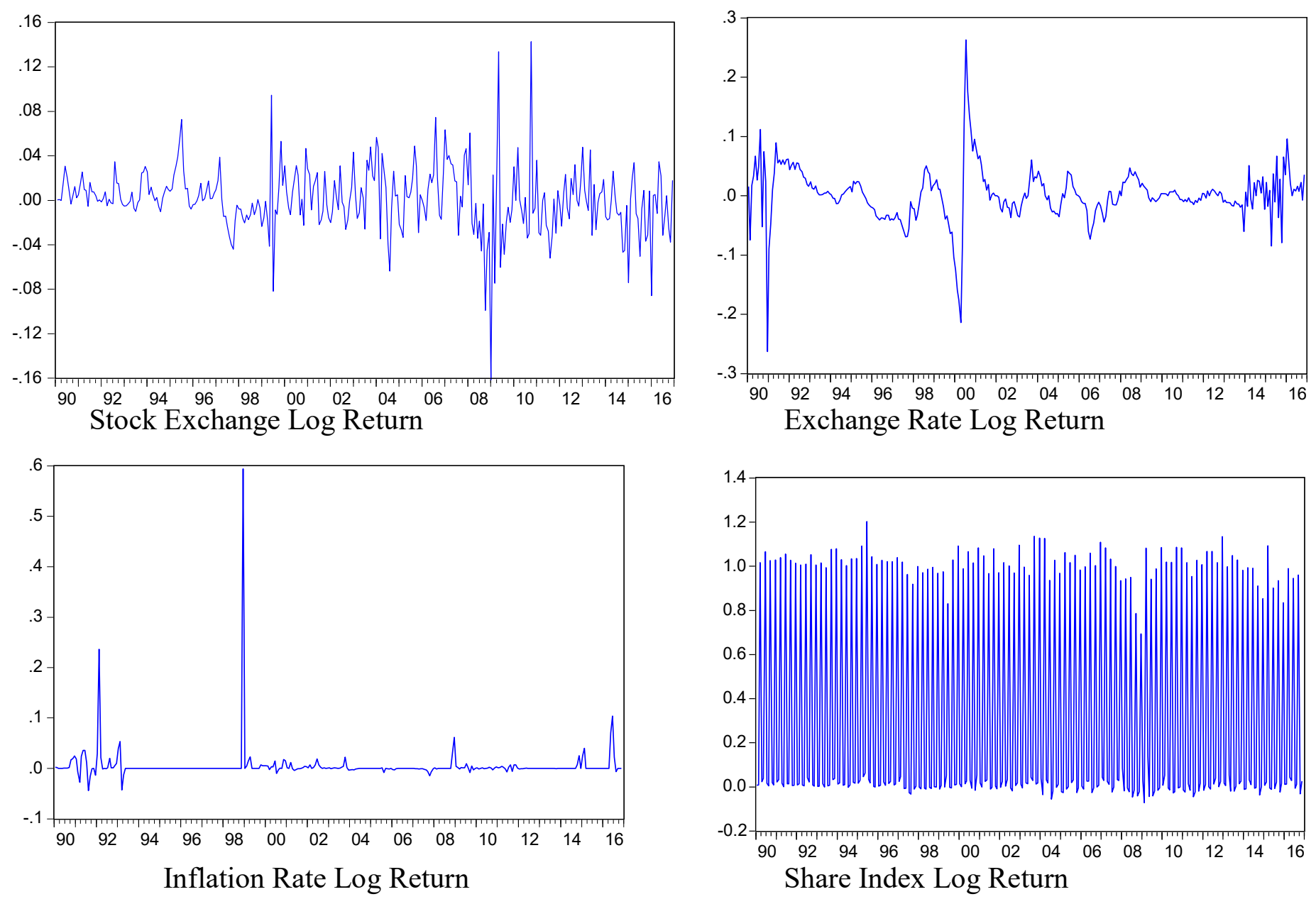

Figure 4. 5. The graphs of monthly log return of Stock exchange, Exchange rate, Inflation rate and Share index respectively 
It was observed in Figure 5 that the log returns of Stock exchange, Exchange rate, Inflation rate and Share index offer evidence of the well-known volatility clustering effect. It is a tendency for volatility in financial markets to appear in bunches. Large returns (of either sign) are expected to follow large returns and small returns (of either sign) to follow small returns (Brooks, 2002).

Table 4.2. Comparing the Four variables under the $\operatorname{Scalar} \operatorname{BEKK}(1,1)$ model

\begin{tabular}{|c|c|c|c|c|c|}
\hline S/N & Variables & Log-likelihood & AIC & SIC & HQIC \\
\hline 1 & Stock Exchange & 728.584 & -4.4866 & -4.4398 & -4.4679 \\
\hline 2 & Exchange Rate & 605.389 & -3.7238 & -3.6769 & -3.7051 \\
\hline 3 & Share Index & -217.804 & 1.3734 & 1.4202 & 1.3921 \\
\hline 4 & Inflation Rate & 705.005 & -4.341 & -4.2938 & -4.3219 \\
\hline
\end{tabular}

LogL (Log-Likelihood) Akaike Information Criteria (AIC), Schwarz Information Criteria (SIC), Hannan-Quim Information Criteria (HQIC)

Table 4.2 shows the model summary of the Scalar BEKK $(1,1)$ for the four variables under consideration, it is clearly that the Nigeria Stock Exchange have the best performance among the four variables with the highest $\log$-likelihood $(\operatorname{LogL})$ of 728.582 and lowest AIC, SIC and HQIC of $-4.4866,-4.4398$ and -4.4679 followed by Inflation rate, Exchange rate and lastly Share Index respectively for the Scalar BEKK $(1,1)$.

Table 4.3 Parameter estimate of the Scalar Bekk $(1,1)$ model

\begin{tabular}{|l|c|c|c|c|}
\hline & Stock Exchange & Exchange Rate & Share Index & Inflation Rate \\
\hline Cstl & 0.012190 & 0.004921 & 0.339243 & 0.000723 \\
S.e & $(0.00136)^{*}$ & $(0.002058)^{*}$ & $(0.026376)^{*}$ & 0.003129 \\
P-value & 0.0000 & 0.0174 & 0.0000 & 0.8175 \\
\hline C_11 & 0.007078 & 0.032613 & 0.388972 & 0.388972 \\
S.e & $(0.00277)^{*}$ & 0.17457 & $(0.025461)^{*}$ & 9.2020 \\
P-value & 0.0111 & 0.8519 & 0.0000 & 0.2280 \\
\hline b_1 & 0.758550 & 0.481571 & 0.574827 & 0.726900 \\
S.e & $(0.07057)^{*}$ & 9.2020 & $(0.08975)^{*}$ & $(0.12856)^{*}$ \\
P-value & 0.0000 & 0.9583 & 0.0000 & 0.0000 \\
\hline a_1 & 0.651605 & 0.000000 & 0.000000 & 0.686736 \\
S.e & $(0.11132)^{*}$ & $(0.00000)^{*}$ & $6.7746 \mathrm{e}-010$ & $(0.08229)^{*}$ \\
P-value & 0.0000 & 0.0000 & 0.3163 & 0.0000 \\
\hline Normality test & 19.928 & 27055. & 481.12 & 21.204 \\
\multicolumn{1}{|c|}{ Chi^2(2) } & {$[0.0000]^{* *}$} & {$[0.0000]^{* *}$} & {$[0.0000]^{* *}$} & {$[0.0000]^{* *}$} \\
\hline LogL & 728.584 & 605.389 & -217.804 & 705.005 \\
\hline
\end{tabular}


Notes: Standard errors (S.e) are in parentheses. * indicates significant at the 5\% level. $\operatorname{LogL}$ and $\mathrm{Chi}^{\wedge} 2(2)$ are the maximum loglikelihood, and Chi-square value at 2 degree of freedom respectively

From Table 4.3 result of the Scalar $\operatorname{BEKK}(1,1)$ model, shows that all the parameters under the Stock exchange are significant at 5\% levels $(\mathrm{p}<0.05)$. For Exchange rate only the constant (Cst1) and a_1 parameters are significant at 5\% levels. For Share Index, only a_1 is not significant and lastly for Inflation both $b_{-} 1$ and a_1 are significant. It was also observed from table 4.3 Scalar BEKK $(1,1)$ model, that the best performance was on Stock Exchange with the highest LogL of 728.584 followed immediately by Inflation rate, Exchange rate and Share Index in that order.

Table 4.4 Comparing the Four variables under the Diagonal $\operatorname{BEKK}(1,1)$ Model

\begin{tabular}{|c|c|c|c|c|c|}
\hline S/N & Variables & Log-likelihood & AIC & SBIC & HQIC \\
\hline 1 & Stock Exchange & 728.581 & -4.4866 & -4.4398 & -4.4679 \\
\hline 2 & Exchange Rate & 605.389 & -3.7238 & -3.6769 & -3.7051 \\
\hline 3 & Share Index & -217.804 & 1.3734 & 1.4202 & 1.3921 \\
\hline 4 & Inflation Rate & 705.005 & -4.3406 & -4.2938 & -4.3219 \\
\hline
\end{tabular}

Table 4.4 shows the model summary of the Diagonal BEKK $(1,1)$ for the four variables under consideration, it shows that the Nigeria Stock Exchange have the best performance among the four variables with the highest log-likelihood $(\operatorname{LogL})$ of 728.581 and lowest AIC, SIC and HQIC of $-4.4866,-4.4398$ and -4.4679 followed by Inflation rate, Exchange rate and Share Index respectively.

Table 4.5 Parameter estimate of the Diagonal Bekk $(1,1)$ Model

\begin{tabular}{|l|c|c|c|c|}
\hline Parameters & Stock Exchange & Exchange Rate & Share Index & Inflation Rate \\
\hline Cstl & 0.012151 & 0.004922 & 0.339292 & 0.000726 \\
S.e & $(0.00136)$ & $(0.00492)$ & $(0.02638)$ & $(0.00313)$ \\
P-value & $0.0000^{*}$ & $0.0175^{*}$ & $0.0000^{*}$ & 0.8168 \\
\hline C_11 & 0.007172 & 0.037185 & 0.411242 & 0.005045 \\
S.e & 0.0028298 & 0.01465 & 0.04213 & 0.004193 \\
P-value & $0.0117^{*}$ & $0.0116^{*}$ & $0.0000^{*}$ & 0.2297 \\
\hline b_1.11 & 0.754999 & 0.006593 & 0.501500 & 0.726763 \\
S.e & 0.071594 & 0.052196 & 0.00000 & 0.12912 \\
P-value & 0.0117 & 0.8996 & 0.0000 & 0.0000 \\
\hline a_1.11 & 0.754999 & 0.000000 & 0.000000 & 0.686881 \\
S.e & 0.11127 & $2.5547 \mathrm{e}-008$ & 0.00000 & 0.082597 \\
P-value & 0.0000 & 0.3822 & 0.0000 & 0.0000 \\
\hline
\end{tabular}




\begin{tabular}{|l|c|c|c|c|}
\hline $\begin{array}{c}\text { Normality test } \\
\mathrm{Chi}^{\wedge} 2(2)\end{array}$ & $\begin{array}{c}19.867 \\
{[0.0000]^{* *}}\end{array}$ & $\begin{array}{c}27055 . \\
{[0.0000]^{* *}}\end{array}$ & $\begin{array}{c}481.12 \\
{[0.0000]^{* *}}\end{array}$ & $\begin{array}{c}21.218 \\
{[0.0000]^{* *}}\end{array}$ \\
\hline Log Likelihood & 728.581 & 605.389 & -217.804 & 705.005 \\
\hline
\end{tabular}

Notes: Standard errors (S.e) are in parentheses. * indicates significant at the 5\% level. LogL and Chi^2(2) are the maximum loglikelihood, and Chi-square value at 2 degree of freedom respectively

From Table 4.5 result of the Diagonal BEKK $(1,1)$ Model, shows that all the parameters under the Stock exchange are significant at 5\% level. For Exchange rate only the constant (Cst1) and C_11 parameters are significant at 5\%. For Share Index all the parameters a_1 are significant and lastly for Inflation both b_1.11 and a_1.11 are significant. It was also observed from table 4.5 the Diagonal BEKK $(1,1)$ Model, that the best performance was on Stock Exchange with the highest LogL of 728.584 followed by Inflation rate, Exchange rate and Share Index in that order.

Table 4.6 Parameter Estimate of the Constant Conditional Correlation (CCC) Model for Univariate GARCH $(1,1)$ model

\begin{tabular}{|l|c|c|c|c|}
\hline Parameters & Stock Exchange & Exchange Rate & Share Index & Inflation Rate \\
\hline rho_21 & 0.012114 & 0.011593 & 0.330531 & 0.001477 \\
S.e & $(0.001234)$ & NA & NA & $(0.00241)$ \\
P-value & $0.0000^{*}$ & NA & NA & 0.5398 \\
\hline Cst(V) $\times 10^{\wedge} 4$ & 0.331173 & 2.132608 & 0.244273 & 0.123685 \\
S.e & $(0.19727)$ & NA & NA & $(0.13319)$ \\
P-value & 0.0942 & NA & NA & 0.3538 \\
\hline ARCH(Alpha1) & 0.567711 & 7.557632 & -0.020195 & 0.602191 \\
S.e & $(0.18902)$ & NA & NA & $(0.15177)$ \\
P-value & $0.0029 *$ & NA & NA & $0.0001 *$ \\
\hline GARCH(Beta1) & 0.549868 & -0.000461 & 1.020284 & 0.533682 \\
S.e & $(0.085454)$ & NA & NA & $(0.11606)$ \\
P-value & $0.0000^{*}$ & NA & NA & $0.0000^{*}$ \\
\hline Mean (Y) & 0.00865 & 0.00492 & 0.33927 & 0.00166 \\
\hline \multicolumn{1}{|c|}{ Variance (Y) } & 0.00086 & 0.00138 & 0.22554 & 0.00210 \\
\hline Skewness (Y) & -0.05194 & 13.21487 & 0.73410 & -0.33950 \\
\hline Kurtosis (Y) & 8.63939 & 201.38850 & 1.57498 & 11.69817 \\
\hline Log Likelihood & 729.865 & 597.569 & -216.764 & 707.995 \\
\hline Alpha[1]+Beta[1] & 1.11758 & 7.55717 & 1.00009 & 1.13587 \\
\hline
\end{tabular}

Notes: Standard errors are in parentheses. * indicates significant at the $5 \%$ level .LogL, AIC, SIC, and HQIC, are the maximum log-likelihood, Alkaike information Criterion, Schwarz information Criterion, Hannan-Quinn information criterion and respectively.

From Table 4.6, based on the assumption of 5\% significance level for CCC model for Garch (1, 1), Both the Alpha1 and Beta1 parameters are significant for Stock exchange and Inflation rate. 
The kurtosis of stock exchange, Exchange rate and inflation are just like the kurtosis of most financial asset returns are larger than three which means that they have too many extreme value to be normally distributed while that of Share Index that is less than three (3) is the reverse.

Table 4.7 Constant Conditional Correlation Garch Model on all the four Variables

\begin{tabular}{|c|c|c|c|c|}
\hline & Stock Exchange & Exchange Rate & $\begin{array}{l}\text { Share } \\
\text { Index }\end{array}$ & Inflation Rate \\
\hline rho_21 & -0.086996 & 0.044103 & 0.010997 & 0.042858 \\
S.e & $(0.02719)$ & $(0.03626)$ & $(0.1901)$ & $(0.05119)$ \\
0.2247 & 0.8493 & 0.4031 \\
\hline P-value & $0.0015^{*}$ & 381.158 & 513.120 & 1438.16 \\
\hline Log Likelihood & 1328.788 & -2.304387 & -3.121485 & -8.849268 \\
\hline Akaike_IC & -8.172061 & -2.305884 & -3.122983 & -8.850766 \\
\hline Shibata_IC & -8.173559 & -2.199127 & -3.016226 & -8.744009 \\
\hline Schwarz_IC & -8.066801 & -2.262368 & -3.079467 & -8.807250 \\
\hline Hannan- & -8.130043 & & & \\
\hline Quinn_IC & & 25427. & 502.22 & 35.295 \\
\hline Vector & 25365. & {$[0.0000]^{* *}$} & {$[0.0000]^{* *}$} & {$[0.0000]^{* *}$} \\
\hline Normality test: & {$[0.0000]^{* *}$} & & \\
Chi^2(4) & & &
\end{tabular}

Notes: Standard errors are in parentheses. * indicates significant at the $5 \%$ level .LogL, AIC, SIC, and HQIC, are the maximum log-likelihood, Alkaike information Criterion, Schwarz information Criterion, Hannan-Quinn information criterion and respectively.

Table 4.7 , based on the assumption of 5\% level of significant for the parameter (rho_21) for CCC model for the four variables under consideration, it was observed that only the Stock Exchange was significant at $0.01,0.05$ and 0.10 significant level with p-value of 0.0015 which is less than $1 \%, 5 \%$, and $10 \%$, and all the other three variable are not significant. It was also observed that the CCC model have best perform on Inflation rate which have the highest $\operatorname{logL}$ of 1438.16 with lowest AIC (-8.849268), Shibata_IC (-8.850766), Schwarz_IC (-8.744009), and Hannan-Quinn_IC (-8.807250) followed immediately by Stock Exchange, Share Index and lastly, Exchange rate with $\log \mathrm{L}$ of 381.158with lowest AIC -2.304387), Shibata_IC (-2.305884), Schwarz_IC (-2.199127), and Hannan-Quinn_IC-2.262368) respectively.

\subsection{Parameter Estimate of the Dynamic Conditional Correlation Model for Univariate}

GARCH $(1,1)$ model

\begin{tabular}{|l|c|c|c|c|}
\hline Parameter & Stock Exchange & Exchange Rate & Share Index & Inflation Rate \\
\hline Cst(M) & 0.012114 & 0.011593 & 0.330531 & 0.001477 \\
S.e & $(0.001234)$ & NA & NA & $(0.002407)$ \\
P-value & $0.0000^{*}$ & NA & NA & 0.5398 \\
\hline Cst(V) $\times 10^{\wedge} 4$ & 0.331173 & 2.132608 & 0.244273 & 0.123685 \\
S.e & $(0.19727)$ & NA & NA & $(0.13319)$ \\
\hline
\end{tabular}




\begin{tabular}{|l|c|c|c|c|}
\hline P-value & 0.0942 & NA & NA & 0.3538 \\
\hline ARCH(Alpha1) & 0.567711 & 7.557632 & 0.020195 & 0.602191 \\
S.e & $(0.18902)$ & NA & NA & $(0.15177)$ \\
P-value & $0.0029^{*}$ & NA & NA & $0.0001^{*}$ \\
\hline GARCH(Beta1) & 0.549868 & 0.000461 & 1.020284 & 0.533682 \\
S.e & $(0.085454)$ & NA & NA & $(0.11606)$ \\
P-value & $0.0000^{*}$ & NA & NA & $0.0000^{*}$ \\
\hline Mean (Y) & 0.00865 & 0.00492 & 0.33927 & 0.00166 \\
\hline \multicolumn{1}{|c|}{ Variance (Y) } & 0.00086 & 0.00138 & 0.22554 & 0.00210 \\
\hline Skewness (Y) & -0.05194 & 13.21487 & 0.73410 & -0.33950 \\
\hline Kurtosis (Y) & 8.63939 & 201.38850 & 1.57498 & 11.69817 \\
\hline Log Likelihood & 729.865 & 597.569 & -216.764 & 707.995 \\
\hline Alpha[1]+Beta[1] & 1.11758 & 7.55717 & 1.00009 & 1.13587 \\
\hline
\end{tabular}

Notes: Standard errors are in parentheses. * indicates significant at the $5 \%$ level .LogL, AIC, SIC, and HQIC, are the maximum log-likelihood, Alkaike information Criterion, Schwarz information Criterion, Hannan-Quinn information criterion and respectively.

From Table 4.8, based on the assumption of 5\% significance level for DCC model for Garch (1, 1), Both the Alpha1 and Beta1 parameters are significant for Stock exchange and Inflation rate .The kurtosis of stock exchange, Exchange rate and inflation are just like the kurtosis of most financial asset returns is larger than three which means that they have too many extreme value to be normally distributed while that of Share Index that is less than three (3) is the reverse The LogL indicates that the model best performed most on Stock Exchange(729.865), followed by Inflation rate (707.995), then exchange rate (597.569) and Share Index (-216.764) which is the least among all the four variables Considered. 
Table 4.9 showing the Dynamic Conditional Correlation Model

\begin{tabular}{|c|c|c|c|c|}
\hline & $\begin{array}{l}\text { Stock } \\
\text { Exchange }\end{array}$ & Exchange Rate & Share Index & Inflation Rate \\
\hline rho_21 & -0.205577 & 0.044099 & 0.010915 & 0.182162 \\
S.e & $(0.08229)$ & $(0.03626)$ & $(0.05785)$ & $(0.10821)$ \\
P-value & $0.0130^{*}$ & 0.2248 & 0.8505 & 0.0933 \\
\hline Alpha & 0.249650 & 0.000000 & 0.000005 & 0.296103 \\
S.e & $(0.084112)$ & $(0.00000)$ & $(0.00000)$ & $(0.09043)$ \\
P-value & $0.0032^{*}$ & 1.0000 & 0.0538 & $0.0012^{*}$ \\
\hline Beta & 0.386787 & 0.900090 & 0.890351 & 0.450565 \\
S.e & $(0.11630)$ & $(0.17456)$ & $(0.09548)$ & $(0.22600)$ \\
P-value & $0.0010 *$ & $0.0000^{*}$ & $0.0000^{*}$ & $0.0470^{*}$ \\
\hline Log Likelihood & 1330.037 & - & 513.120 & 1452.807 \\
\hline Akaike_IC & -8.167411 & -2.292003 & -3.109101 & -8.927598 \\
\hline Shibata_IC & -8.169631 & -2.294222 & -3.057745 & -8.929817 \\
\hline Schwarz_IC & -8.038761 & -2.163352 & -2.980450 & -8.798947 \\
\hline Hannan-Quinn_IC & -8.116055 & -2.240647 & -3.057745 & -8.876242 \\
\hline Vector Normality & 24359 & 25427. & 502.26 & 38.885 \\
test: & {$[0.0000]^{* *}$} & {$[0.0000]^{* *}$} & {$[0.0000]^{* *}$} & {$[0.0000]^{* *}$} \\
\hline Chi^2(4) & & & & \\
\hline
\end{tabular}

Notes: Standard errors are in parentheses. * indicates significant at the 5\% level. LogL, AIC, SIC, and HQIC, are the maximum log-likelihood, Alkaike information Criterion, Schwarz information Criterion, Hannan-Quinn information criterion and respectively.

Table 4.9, based on the assumption of $5 \%$ level of significant for the parameter (rho_21) for DCC model for the four variables under consideration, it was observed that the Alpha and Beta parameters are significant at 0.01, 0.05 and 0.10 significant level for both Stock Exchange and inflation rate while only the Beta parameter is significant for both exchange rate and the Share Index. It was also observed that the DCC model have best performance on Inflation rate which have the highest $\operatorname{logL}$ of 1452.807with lowest AIC(.927598), Shibata_IC (-8. 929817), Schwarz_IC (-8. 798947), and Hannan-Quinn_IC (8.876242) followed immediately by Stock Exchange, Share Index and lastly, Exchange rate with $\log L$ of 381.158 with lowest Akaike_IC (-2. 29203), Shibata_IC (-2. 294222), Schwarz_IC (-2.163352), and Hannan-Quinn_IC (-2. 240647) respectively. 
Table 4.10 Parameter Estimates of Multivariate GARCH models for Stock Exchange

\begin{tabular}{|c|c|c|c|c|}
\hline Parameter & Scalar Bekk $(1,1)$ & Diagonal BEKK $(1,1)$. & $\mathrm{CCC}$ & DCC \\
\hline $\begin{array}{c}\text { Cst1 } \\
\text { S.e } \\
\text { P-value }\end{array}$ & $\begin{array}{c}0.012190 \\
(0.00136) \\
0.0000 *\end{array}$ & $\begin{array}{c}0.012151 \\
(0.001363) \\
0.0000^{*}\end{array}$ & - & - \\
\hline $\begin{array}{c}\text { C_11 } \\
\text { S.e } \\
\text { P-value }\end{array}$ & $\begin{array}{c}0.007078 \\
0.00277 \\
0.0111 *\end{array}$ & $\begin{array}{c}0.007172 \\
0.0028298 \\
0.0117^{*}\end{array}$ & - & - \\
\hline $\begin{array}{c}\text { b_1(b_1.11) } \\
\text { S.e } \\
\text { P-value }\end{array}$ & $\begin{array}{c}0.758550 \\
(0.07057) \\
0.0000 *\end{array}$ & $\begin{array}{c}0.754999 \\
(0.07159) \\
0.0117 *\end{array}$ & - & - \\
\hline $\begin{array}{c}\text { a_1(a_1.11) } \\
\text { S.e } \\
\text { P-value }\end{array}$ & $\begin{array}{c}0.651605 \\
(0.11132) \\
0.0000^{*}\end{array}$ & $\begin{array}{c}0.754999 \\
(0.11127) \\
0.0000 *\end{array}$ & - & - \\
\hline $\begin{array}{c}\text { Cst }(\mathrm{V}) \times 10^{\wedge} 4 \\
\text { S.e } \\
\text { P-value }\end{array}$ & - & - & - & - \\
\hline $\begin{array}{c}\text { rho_21 } \\
\text { S.e } \\
\text { P-value }\end{array}$ & - & - & $\begin{array}{c}-0.086996 \\
(0.02719) \\
0.0015^{*}\end{array}$ & $\begin{array}{c}-0.205577 \\
(0.08229) \\
0.0130 *\end{array}$ \\
\hline $\begin{array}{c}\text { ARCH(Alpha1) } \\
\text { S.e } \\
\text { P-value }\end{array}$ & - & - & - & $\begin{array}{c}0.249650 \\
(0.08411) \\
0.0032 *\end{array}$ \\
\hline $\begin{array}{c}\text { GARCH(Beta } 1) \\
\text { S.e } \\
\text { P-value }\end{array}$ & - & - & - & $\begin{array}{c}0.386787 \\
(0.11630) \\
0.0010^{*}\end{array}$ \\
\hline $\log \mathrm{L}$ & 728.584 & 728.581 & 1328.788 & 1330.037 \\
\hline $\begin{array}{l}\text { Normality test } \\
\mathrm{Chi}^{\wedge} 2(2)\end{array}$ & $\begin{array}{c}19.928 \\
{[0.0000]^{* *}}\end{array}$ & $\begin{array}{c}19.867 \\
{[0.0000]^{* *}}\end{array}$ & $\begin{array}{c}25365 . \\
{[0.0000]^{*}} \\
*\end{array}$ & $\begin{array}{c}24359 \\
{[0.0000]^{* *}}\end{array}$ \\
\hline $\mathrm{AIC}$ & -4.4866 & -4.4866 & -8.172061 & -8.167411 \\
\hline SIC & -4.4398 & -4.4398 & -8.066801 & -8.038761 \\
\hline HQIC & -4.4679 & -4.4679 & -8.130043 & -8.116055 \\
\hline
\end{tabular}

Notes: Standard errors are in parentheses. * indicates significant at the 5\% level .LogL, AIC, SIC, and HQIC, are the maximum log-likelihood, Alkaike information Criterion, Schwarz information Criterion, Hannan-Quinn information criterion and respectively.

Table 4.10 shows that the coefficients of all the parameters are positive at 5\% level. DCC Model was fitted, were the coefficients for all the parameters are positive while that of the correlationTargeting (rho_21) is negative and they are very close to 1 and -1 , indicating that high 
persistence in the conditional variances. The Model DCsC, satisfied the properties of a good model of conditional mean and variance of the confidential Interval (C.I) of 1 and -1 that is the conditional variance is finite and the series are strictly stationary. The Nigerian Stock Exchange will experience a non- steady shock in the Stock market. (Samson \&Akinwande, 2017).

Table 4.11 Parameter Estimates of Multivariate GARCH models for Exchange rate

\begin{tabular}{|c|c|c|c|c|}
\hline & Scalar Bekk $(1,1)$ & Diagonal BEKK $(1,1)$. & $\mathrm{CCC}$ & $\overline{\text { DCC }}$ \\
\hline $\begin{array}{c}\text { Cst1 } \\
\text { S.e } \\
\text { P-value }\end{array}$ & $\begin{array}{c}0.339243 \\
0.026376 \\
0.0000\end{array}$ & $\begin{array}{c}0.339292 \\
0.026378 \\
0.0000\end{array}$ & - & - \\
\hline $\begin{array}{c}\text { C_11 } \\
\text { S.e } \\
\text { P-value }\end{array}$ & $\begin{array}{l}0.38897 \\
(0.0255) \\
0.0000^{*}\end{array}$ & $\begin{array}{c}0.411242 \\
(0.04213) \\
0.0000^{*}\end{array}$ & - & - \\
\hline $\begin{array}{c}\text { b_1(b_1.11) } \\
\text { S.e } \\
\text { P-value }\end{array}$ & $\begin{array}{c}0.574827 \\
(0.08975) \\
0.0000^{*}\end{array}$ & $\begin{array}{c}0.501500 \\
(0.00000) \\
0.0000^{*}\end{array}$ & - & - \\
\hline $\begin{array}{c}\text { a_1(a_1.11) } \\
\text { S.e } \\
\text { P-value }\end{array}$ & $\begin{array}{c}0.000000 \\
(0.00000) \\
0.3163 \\
\end{array}$ & $\begin{array}{c}0.000000 \\
(0.00000) \\
0.0000^{*}\end{array}$ & - & - \\
\hline $\begin{array}{c}\text { Cst }(\mathrm{V}) \times 10^{\wedge} 4 \\
\text { S.e } \\
\text { P-value }\end{array}$ & - & - & - & - \\
\hline $\begin{array}{l}\text { rho_21 } \\
\text { S.e } \\
\text { P-value }\end{array}$ & - & - & $\begin{array}{c}0.010997 \\
(0.1901) \\
0.8493\end{array}$ & $\begin{array}{c}0.010915 \\
(0.05785) \\
0.8505\end{array}$ \\
\hline $\begin{array}{c}\text { ARCH(Alpha1) } \\
\text { S.e } \\
\text { P-value }\end{array}$ & - & - & - & $\begin{array}{c}0.000005 \\
(0.00000) \\
0.0538\end{array}$ \\
\hline $\begin{array}{c}\text { GARCH(Beta1) } \\
\text { S.e } \\
\text { P-value } \\
\end{array}$ & - & - & - & $\begin{array}{c}0.890351 \\
(0.09548) \\
0.0000^{*}\end{array}$ \\
\hline $\log \mathrm{L}$ & -217.804 & -217.804 & 513.120 & 513.120 \\
\hline $\begin{array}{l}\text { Normality test } \\
\text { Chi^}^{\wedge} 2(2) /(4)\end{array}$ & $\begin{array}{c}481.12 \\
{[0.0000]^{* *}}\end{array}$ & $\begin{array}{c}481.12 \\
{[0.0000]^{* *}}\end{array}$ & $\begin{array}{c}502.22 \\
{[0.0000]^{* *}}\end{array}$ & $\begin{array}{c}502.26 \\
{[0.0000]^{* *}}\end{array}$ \\
\hline AIC & 1.3734 & 1.3734 & -3.121485 & -3.109101 \\
\hline SIC & 1.4202 & 1.4202 & -3.016226 & -2.980450 \\
\hline HQIC & 1.3921 & 1.3921 & -3.079467 & -3.057745 \\
\hline
\end{tabular}

Notes: Standard errors are in parentheses. * indicates significant at the 5\% level. LogL, AIC, SIC, and HQIC, are the maximum log-likelihood, Alkaike information Criterion, Schwarz information Criterion, Hannan-Quinn information criterion and respectively. 
Table 4.11 shows that the coefficients of all the parameters and correlation-Targeting value are all positive at $5 \%$ level. The DCC Model shows that alpha1 + beta $1=0.000000+0.900000<1$ and rho_21 (correlation Targeting) $=0.044103>-1$, both of them are very close to 1 and -1 , indicating that high persistence in the conditional variance. This also means that conditional variance is finite and the series are strictly stationary, thus the Exchange Rate will experience a volatility in Nigeria stock market. (Samson \& Akinwande,2017).

Table 4.12 Parameter Estimates of Multivariate GARCH models for Share Index

\begin{tabular}{|c|c|c|c|c|}
\hline & Scalar Bekk $(1, \mathbf{1})$ & Diagonal BEKK $(1,1)$. & $\mathrm{CCC}$ & DCC \\
\hline $\begin{array}{c}\text { Cst1 } \\
\text { S.e } \\
\text { P-value }\end{array}$ & $\begin{array}{l}0.004922 \\
0.004922 \\
(0.0175)^{*}\end{array}$ & $\begin{array}{l}0.004922 \\
0.004922 \\
(0.0175)^{*}\end{array}$ & - & - \\
\hline $\begin{array}{c}\text { C_11 } \\
\text { S.e } \\
\text { P-value }\end{array}$ & $\begin{array}{l}0.037185 \\
0.014654 \\
(0.0116)^{*}\end{array}$ & $\begin{array}{l}0.037185 \\
0.014654 \\
(0.0116)^{*}\end{array}$ & - & - \\
\hline $\begin{array}{c}\text { b_1(b_1.11) } \\
\text { S.e } \\
\text { P-value }\end{array}$ & $\begin{array}{c}0.006593 \\
(0.052196) \\
0.8996\end{array}$ & $\begin{array}{c}0.006593 \\
(0.052196) \\
0.8996\end{array}$ & - & - \\
\hline $\begin{array}{c}\text { a_1(a_1.11) } \\
\text { S.e } \\
\text { P-value }\end{array}$ & $\begin{array}{c}0.000000 \\
(0.00000) \\
0.3822 \\
\end{array}$ & $\begin{array}{c}0.000000 \\
(0.00000) \\
0.3822 \\
\end{array}$ & - & - \\
\hline $\begin{array}{c}\text { Cst }(\mathrm{V}) \times 10^{\wedge} 4 \\
\text { S.e } \\
\text { P-value }\end{array}$ & - & - & - & - \\
\hline $\begin{array}{c}\text { rho_21 } \\
\text { S.e } \\
\text { P-value }\end{array}$ & - & - & $\begin{array}{c}0.044103 \\
(0.036255) \\
0.2247\end{array}$ & $\begin{array}{c}0.044099 \\
(0.03626) \\
0.2248\end{array}$ \\
\hline $\begin{array}{c}\text { ARCH(Alpha1) } \\
\text { S.e } \\
\text { P-value } \\
\end{array}$ & - & - & - & $\begin{array}{c}0.000000 \\
(0.00000) \\
1.0000 \\
\end{array}$ \\
\hline $\begin{array}{c}\text { GARCH(Beta1) } \\
\text { S.e } \\
\text { P-value }\end{array}$ & - & - & - & $\begin{array}{l}0.900090 \\
(0.17456) \\
(0.0000)^{*}\end{array}$ \\
\hline $\log L$ & 605.389 & 605.389 & 1381.158 & 1430.101 \\
\hline $\begin{array}{l}\text { Normality test } \\
\text { Chi^}^{\prime} 2(2) /(4)\end{array}$ & $\begin{array}{c}27055 . \\
{[0.0000]^{* *}}\end{array}$ & $\begin{array}{c}27055 . \\
{[0.0000]^{* *}}\end{array}$ & $\begin{array}{c}25427 . \\
{[0.0000]^{* *}}\end{array}$ & $\begin{array}{c}25427 . \\
{[0.0000]^{* *}}\end{array}$ \\
\hline AIC & -3.7238 & -3.7238 & -2.304387 & -2.292003 \\
\hline SIC & -3.6769 & -3.6769 & -2.199127 & -2.980450 \\
\hline HQIC & -3.7051 & -3.7051 & 2.262368 & -3.057745 \\
\hline
\end{tabular}

Notes: Standard errors are in parentheses. * indicates significant at the $5 \%$ level. LogL, AIC, SIC, and HQIC, are the maximum log-likelihood, Alkaike information Criterion, Schwarz information Criterion, Hannan-Quinn information criterion and respectively. 
Table 4.12 shows that the coefficients of all the parameters and correlation-Targeting values are all positive at $5 \%$ level. The DCC Model shows that alpha1 + beta1 $=0.000005+0.890351=$ $0.890356<1$ and rho_21 (correlation Targeting) $=0.010915>-1$, both of them are very close to 1 and -1 , indicating that there is high persistence in the conditional variance. This also means that conditional variance is finite and the series are strictly stationary, The Nigeria Share Index will experience non-steady shock in the stock market. (Samson \& Akinwande,2017).

Table 4.13 Parameter Estimates of Multivariate GARCH models for Inflation rate

\begin{tabular}{|c|c|c|c|c|}
\hline Parameter & Scalar Bekk $(1,1)$ & Diagonal BEKK $(1,1)$. & $\mathrm{CCC}$ & DCC \\
\hline $\begin{array}{c}\text { Cst1 } \\
\text { S.e } \\
\text { P-value }\end{array}$ & $\begin{array}{c}0.000723 \\
(0.00313) \\
0.8175\end{array}$ & $\begin{array}{c}0.000726 \\
(0.00313) \\
0.8168\end{array}$ & - & - \\
\hline $\begin{array}{c}\text { C_11 } \\
\text { S.e } \\
\text { P-value }\end{array}$ & $\begin{array}{c}0.388972 \\
(9.2020) \\
0.2280\end{array}$ & $\begin{array}{c}0.005045 \\
(0.00419) \\
0.2297\end{array}$ & - & - \\
\hline $\begin{array}{c}\text { b_1(b_1.11) } \\
\text { S.e } \\
\text { P-value }\end{array}$ & $\begin{array}{c}0.726900 \\
(0.12856) \\
0.0000^{*}\end{array}$ & $\begin{array}{c}0.726763 \\
(0.12912) \\
0.0000^{*}\end{array}$ & - & - \\
\hline $\begin{array}{l}\text { a_1(a_1.11) } \\
\text { S.e } \\
\text { P-value }\end{array}$ & $\begin{array}{c}0.686736 \\
(0.08229) \\
0.0000^{*}\end{array}$ & $\begin{array}{c}0.686881 \\
(0.08260) \\
0.0000^{*}\end{array}$ & - & - \\
\hline $\begin{array}{c}\text { Cst(V) } \times 10^{\wedge} 4 \\
\text { S.e } \\
\text { P-value }\end{array}$ & - & - & - & - \\
\hline $\begin{array}{l}\text { rho_21 } \\
\text { S.e } \\
\text { P-value }\end{array}$ & - & - & $\begin{array}{c}0.042858 \\
(0.05119) \\
0.4031 \\
\end{array}$ & $\begin{array}{c}0.182162 \\
(0.10821) \\
0.0933\end{array}$ \\
\hline $\begin{array}{c}\text { ARCH(Alpha1) } \\
\text { S.e } \\
\text { P-value }\end{array}$ & - & - & - & $\begin{array}{c}0.296103 \\
(0.09043) \\
0.0012 *\end{array}$ \\
\hline $\begin{array}{c}\text { GARCH(Beta1) } \\
\text { S.e } \\
\text { P-value }\end{array}$ & - & - & - & $\begin{array}{c}0.450565 \\
(0.22600) \\
0.0470^{*}\end{array}$ \\
\hline $\log \mathrm{L}$ & 705.005 & 705.005 & 1438.16 & 1452.807 \\
\hline $\begin{array}{l}\text { Normality test } \\
\text { Chi^}^{\wedge} 2(2) /(4)\end{array}$ & $\begin{array}{c}21.204 \\
{[0.0000]^{* *}}\end{array}$ & $\begin{array}{c}21.218 \\
{[0.0000]^{* *}}\end{array}$ & $\begin{array}{c}35.295 \\
{[0.0000]^{* *}}\end{array}$ & $\begin{array}{c}38.885 \\
{[0.0000]^{* *}}\end{array}$ \\
\hline AIC & -4.341 & -4.3406 & -8.84927 & -8.927598 \\
\hline SIC & -4.2938 & -4.2938 & -8.74401 & -8.798947 \\
\hline HQIC & -4.3219 & -4.3219 & -8.80725 & -8.876242 \\
\hline
\end{tabular}

Notes: Standard errors are in parentheses. * indicates significant at the 5\% level. LogL, AIC, SIC, and HQIC, are the maximum log-likelihood, Alkaike information Criterion, Schwarz information Criterion, Hannan-Quinn information criterion and respectively 
Table 4.13 shows that the coefficients of all the parameters are positive at 5\% level. DCC Model was fitted, were the coefficients for all the parameters and that of the correlation-Targeting (rho_21) are positive and they are very close to 1 and -1, indicating that high persistence in the conditional variances. The Model DCC, satisfied the properties of a good model of conditional mean and variance of the confidential Interval (C.I) of 1 and -1 that is the conditional variance is finite and the series are strictly stationary. The Nigerian Inflation rate will experience a nonsteady shock in the Stock market. (Samson \&Akinwande, 2017).

\subsection{Discussion of Findings}

The relevant descriptive statistics in the context of this study are mean, median, maximum, minimum, standard deviation, skewness, kurtosis, jarque-bera test and p-values. These statistics were computed for the monthly data set of inflation rate, exchange rate, share index, stock exchange from January, 1990 to December, and 2016.Table 4.1 presents the summarized results of the descriptive statistics and the average values of inflation rate, exchange rate, share index and stock exchange are 18.7427, 101.2375, 17752.57 and 3695.994 respectively. The wide gaps between the maximum and minimum series give supportive evidence to the high level of variability (volatility) in Nigeria stock Market. Stock exchange has the highest standard deviation (4306.888) this means that the most volatile variable among these variables is stock exchange. The data for exchange rate are approximately symmetric since its skewness is between -0.5 and +0.5 (Atoi, 2014). The distribution of data set for share index and stock exchange are moderately skewed. The kurtosis values of exchange are positive and appear to be smaller than 3 implying that they variables are all platykurtic in nature while the kurtosis of inflation rate is greater than 3 implying that it is leptokurtic in nature (highly peaked than the normal). This in line with the work of Engle and Patton (2001), while in the case of inflation rate, share index and stock exchange, the probabilities of the Jarque-Bera (JB) statistics are zeros less than the 5\% level of significance. Thus, null hypothesis which state that the data are normally distributed is rejected at $5 \%$ level of significance.

However, the probability of the JB statistics for exchange rate is 0.3360 greater than $5 \%$ level of significance since (P-value) hence, exchange rate is normally distributed. Figure 5 represents graphs of the return series of the variables. Table 4.3. and Table 4.5 compare the four variables under the scalar $\operatorname{BEKK}(1,1)$ model and diagonal $\operatorname{BEKK}(1,1)$ model and clearly revealed that Nigeria stock exchange has the best performance among the variables with highest log-likehood 
and minimum information criteria. Tables4.6 and 4.8 .revealed that theuniverate models are unfit and non-stationary according the assumption that if the mean reverting rate $\left(\alpha_{1}+\beta_{1}\right)$ is greater than one and since the volatility will eventually explode to infinity (Banerjee and Sarkar, 2006). Thus it becomes impossible to forecast with the univariate GARCH models due to its instability. Tables 4.10, 4.11, 4.12 and 4.13 show that the coefficients of all the parameters are positive at $5 \%$ level. DCC Model was fitted, were the coefficients for all the parameters and that of the correlation-Targeting (rho_21) are positive and they are very close to 1 and -1 , indicating that high persistence in the conditional variances. The Model DCC, satisfied the properties of a good model of conditional mean and variance of the confidential Interval (C.I) of 1 and -1 that is the conditional variances are finites and their series are strictly stationary. The Nigerian Stock Exchange, Exchange rate, share index and Inflation rate will experience non- steady shock (volatility) in the Stock market. (Samson \&Akinwande, 2017). In each of these variables, the mean reverting rate $\left(\alpha_{1}+\beta_{1}\right)$ and volatility half-life was calculated using the formula described in section 3.8. For stock exchange, the reverting rate $\left(\alpha_{1}+\beta_{1}\right)$ was 0.6364 and the volatility half-life was calculated to be 1.5 month (one month and fifteen days). For exchange rate, the mean reverting rate $\left(\alpha_{1}+\beta_{1}\right)$ was 0.9000 and the volatility half-life was calculated to be 6.5 months (six months and fifteen days).For share index, the mean reverting rate $\left(\alpha_{1}+\beta_{1}\right)$ was 0.8904 and the volatility half-life was calculated to be 6 months.For inflation rate, the mean reverting rate $\left(\alpha_{1}+\beta_{1}\right)$ was 0.7467 and the volatility half-life was calculated to be 2.4 months (two months and twelve days). By implication, in all these four cases, the volatility had a long memory, persistence and mean-reverting(Banerjee and Sarkar, 2006).

In summary, the univariate models revealed instability and explosion to infinity of volatility. As a result, making it impossible to make forecast on the variables in Nigeria stock market. DCC Model was fitted, the coefficients for all the parameters and that of the correlation-Targeting (rho_21) are positive and they are very close to 1 and -1, indicating that high persistence in the conditional variances. The Model DCC, satisfied the properties of a good model of conditional mean and variance of the confidential Interval (C.I) of 1 and -1 that is the conditional variances are finites and their series are strictly stationary. The Nigerian Stock Exchange, Exchange rate, share index and Inflation rate will experience non- steady shock (volatility) in the Stock market. (Samson \&Akinwande, 2017) .Each of these variables have different length of returning to normalcy after shock ranging from 1.5 month, 6.5 months, 6months to 2,4 months, accordingly. 


\subsection{Conclusions and Recommendations}

The return series of the variables also shows periods of low and high volatilities, which signify volatility clustering. The parameters of the four variables are estimated and compared using Multivariate Garch models. The Model DCC, satisfied the properties of a good model of conditional mean and variance of the confidential Interval (C.I) of 1 and -1 that is the conditional variances are finites and their series are strictly stationary. The Nigerian Stock Exchange, Exchange rate, share index and Inflation rate will experience non- steady shock (volatility) in the Stock market (Samson \& Akinwande, 2017) .Each of these variables have different length of returning to normalcy after shock ranging from 1.5 month, 6.5 months, 6 months to 2,4 months, respectively. The findings from this study raise some policy issues and recommendations, which will reinforce the link between the stock exchange, exchange rate, share index and inflation rate in Nigerian Stock market as follows:

(i) That market information should be allowed to flow unhindered and aggressive trading on a wide range of securities be encouraged so as to increase market depth.

(ii) Investors should be wary of period of instability in the Nigeria Stock market as volatility is bound to be sustained for relatively long period of time.

(iii) Investors and other players in the Nigerian Stock market should be able to sift and distinguish good news from bad news as market return discriminates the response to each. Thus investors should refrain from investing just before the market receives bad news as the momentum of the effect (loss) will take relatively longer time to subdue.

(iv) Investor can invest immediately before the announcement of good news and divest not long afterwards as the positive effect of the market will only last a relatively shorter period of time.

(v) Extensions of this work using a combination of concepts from half-life and the unconditional variance extracted from the fitted variance model would be worthwhile. It will improve upon investors' knowledge on their investing ability and chances. 


\section{REFERENCES}

Adamu, P, A (2005). The Impact of Exchange Rate Volatility on Private Investment in Nigeria; An Error Correction Representation. The Nigeria journal of economics and social studies, 47(2):301-317.

Adeoye, B. W. and Atanda, A. A. (2012). Exchange rate volatility in Nigeria: Consistency, Persistency and Severity. CBN Journal of Applied Statistics, 2(2):29-49

Alam, Z. and Rahman, A. (2012). Modelling volatility of the BDT/USD exchange rate with GARCH Model. Int. Journal of Economics and Finance, 4(11):193-204.

Anderson, T. G., Bollerslev, T., Diebold, F. X. And Labys, P. (2003). Modelling and Forecasting Realized Volatility. Econometrica, 71:529-626

Anyaele and Ogbonna C. (2001), "An Investigation of Capital Market Performance of Nigerian Institutional Investors”, Unpublished MBA project. Banking and Finance, UNEC.

Anyafo R. A. (1994). Exchange Rate, Volatility, Stock Price fluctuations and the leading Behaviour of banks in Nigeria. Journal of economics and international Finance, 2(11):251-260.

Armed P.A. (1992) “The Role of CBN in Capital Market Development: Nigerian Experience”, CBN 6(4): 25-30.

Atoi, N. V. (2014). Testing Volatility in Nigeria Stock Market using GARCH models. CBN Journal of Applied Statistics, 5(2):65-85.

Awogbemi, C. And Alagbe, S. (2011). Emperical Modelling of Nigerian Exchange Rate Volatility. Mathematical Theory and Modelling, 1(3): 1-15.

Bala, D.A and Takimoto, T (2017). "Stock Markets Volatility Spillovers during Financial Crises: A DCC-MGARCH with skewed- $t$ density approach"17: 25-48.

Bala, D.A and Asemota, J. O. (2013). Exchange Rate Volatility in Nigeria; Application of GARCH Models with Exogenous Break. CBN Journal of Applied Statistics, 4(1): 89-116.

Banerjee and Sarkar (2006). A Long Memory property of Stock returns and a New Model. Journal of Empirical Finance, 1:83-106

Bauwens, L., Laurent, S. \&Rombouts, J. V. K. (2006) Multivariate GARCH models: A Survey. Journal of Applied Econometrics 21: 79-109.

Bollerslev, T. (1990) Modelling the coherence in short-run nominal exchange rates: A Multivariate generalized ARCH model, Review of Economics and Statistics, 72:498-505.

Bollerslev, T., Engle, R.F. and Wooldridge, J. (1988) A Capital Asset Pricing Model with Time Varying Covariances. Journal of Political Economy, 96: 116-131. 
Brooks, C., Burke, S., Persand, G., (2003). "Multivariate GARCH Models: Software Choice and Estimation Issues", Journal of Applied Econometrics, 18(6): 725-734

Donwa, P. and Odia, J. (2010) "An Empirical Analysis of the Impact of the Impact of the Nigerian Capital Market on Her Socio-Economic Development”, Journal of Social Sciences, 24 (2) :135-142

Eke, C. (2016). "Comparative Analysis of Normal and Logistic Distributions Modeling of Stock Exchange Monthly returns in Nigeria”. International Journal of Business \& law Research 4(4):58-66.

Emenike K.O. and Peter I.A (2014). "The nature of domestic volatility transmission between sectors of the Nigerian economy" ACRN Journal of Finance and Risk Perspectives3(3):92 - 102

Engle, R. F. (1982). Autoregressive Conditional Heteroscedasticity with Estimate of Variance of United Kingdom Inflation. Econometrica, 50: 987-1007.

Engle, R. F., Forcard, S. M. and Fabozzi, F. (2005). "ARCH/GARCH Models in Applied Financial Econometrics”. Journal of Econometrics and Financial, 20(4): 109 - 133.

Engle, R. F. And Patton A. J.(2001). What good is a Volatility model? Global Finance Journal,11:237-245.

Friedman, R, and Sanddorf-Kohle, W. (2002). Volatility Clustering and Nontrading days in Chinese Stock Markets, Journal of Economics and Business, 54:193-217.

Hafner, Ch. Herwartz, H. (2006). "Volatility impulse response for multivariate GARCH models: An exchange rate illustration", Journal of International Money and Finance, 45(4):1-22

Hongyu, P. and Zhichao, Z. (2006). "Forecasting Financial Volatility: Evidence from Chinese Stock Market”. Working paper in Economics and Finance Conference, 2: 63 - 86.

Ibrahim, M. (2016). "Modelling volatility in the Nigeria Stock Market" Journal of Business and Economics Statistics,20:351-362.

Murekachiro, D. (2016). "Time Series Volatility Forecasting of the Zimbabwean Stock Exchange". The International Journal of Business \& Management 10(5):221-240.

Olayiwola, O.M., Amalare, A.A and Adebesin S.O. (2016). "Prediction of Returns on AllShare Index of Nigeria Stock Exchange" .The Pacific Journal of Science and Technology 17(1):67-74.

Onoh, J. K. (2002), Dynamics of Money Banking and Finance in Nigeria. An Emerging Market Aba; Astramerida publishing.

Onwukwe, C.E., Bassey B.E. and Isaac I.O (2011). "On Modeling the Volatility of Nigerian 
Stock Returns Using GARCH Models". Journal of Mathematics Research 4( 3):56-87

Okafor, F: (1996), Investment Decision. Evaluation of Projects and securities. Enugu: Gosfak printing" and publishing Coy Limited.

Okpara, G. C. (2010) "Analysis of Weak-Form Efficiency on the Nigerian Stock Market:

Evidence from GARCH Model", The International Journal of Applied Economics and

Finance, $4: 62-66$.

Osahon, O.H. (2014). "Measuring Nigerian Stock Market Volatility”. Singaporean Journal of Business Economics, and Management studies 2(8):211-221

Osaze, E. B. (2000) The Nigerian Capital Market in the African and Global Financial System.5(3): 113-123.

Tse, Y.K, and Tsui, A.K.C. (1999) "A note on diagnosing multivariate conditional Heteroscedasticity models", Journal of time series analysis, 20(6): 679-691

Samson, A. and Akinwande, M.O.(2017) "Relationship between Nigeria Stock Exchange and Inflation to Dynamic Conditinal Correlation Model" Journal of Statistical Application and Probability 4(2):51-56

Yaya, O.S, Abiodun, S. and Atoi, N. V. (2016). "Volatility in the Nigerian Stock Market: Empirical Application of Beta-t-GARCH Variants". CBN Journal of Applied Statistics 7(2):1-6.

Yaya, O.S., Shittu, O. I. (2010). On the impact of inflation and exchange rate on conditional Stock Market Volatility: CBN Journal of Applied Statistics, 5(2):65-92. 